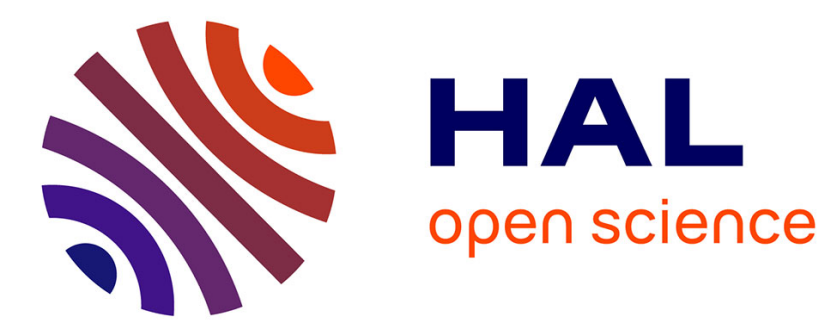

\title{
Development of a TiAl Alloy by Spark Plasma Sintering
}

Alain Couret, Thomas Voisin, Marc Thomas, Jean-Philippe Monchoux

\section{To cite this version:}

Alain Couret, Thomas Voisin, Marc Thomas, Jean-Philippe Monchoux. Development of a TiAl Alloy by Spark Plasma Sintering. JOM Journal of the Minerals, Metals and Materials Society, 2017, 69 (12), pp.2576 - 2582. 10.1007/s11837-017-2549-6 . hal-01907525

\section{HAL Id: hal-01907525 \\ https://hal.science/hal-01907525}

Submitted on 29 Oct 2018

HAL is a multi-disciplinary open access archive for the deposit and dissemination of scientific research documents, whether they are published or not. The documents may come from teaching and research institutions in France or abroad, or from public or private research centers.
L'archive ouverte pluridisciplinaire HAL, est destinée au dépôt et à la diffusion de documents scientifiques de niveau recherche, publiés ou non, émanant des établissements d'enseignement et de recherche français ou étrangers, des laboratoires publics ou privés. 


\title{
Development of A TiAl alloy by SPARk Plasma Sintering
}

\author{
ALAIN COURET ${ }^{1,3}$, THOMAS VOISIN ${ }^{1}$, MARC THOMAS ${ }^{2}$ and JEAN- \\ PHILIPPE MONCHOUX ${ }^{1}$ \\ 1.- CNRS ; CEMES (Centre d'Elaboration de Matériaux et d'Etudes Structurales) ; BP \\ 94347, 29 rue J. Marvig, F-31055 Toulouse, France \\ 2.- ONERA/DMAS, 29 Avenue de la Division Leclerc, BP 72, 92322 Châtillon Cedex, \\ France \\ 3.- email : alain.couret@cemes.fr
}

Spark Plasma Sintering (SPS) is a consolidated powder metallurgy process for which the powder sintering is achieved through an applied electric current. The present paper aims at describing the method we employed to develop a TiAl-based alloy adjusted for this SPS process. Owing to its enhanced mechanical properties, this alloy was found to fully match the industrial specifications for aeronautic and automotive industries that require a high strength at high temperature and a reasonably good ductility at room temperature.

A step by step method was followed for this alloy development. Starting from a basic study on the as-SPSed GE alloy (Ti-48Al-2Cr-2Nb) in which the influence of the microstructure was studied, the microstructure - alloy composition relationships were then investigated to increase the mechanical properties. As a result of this study, we concluded that tungsten had to be the major alloying element to improve the resistance at high temperature and a careful addition of boron would serve the properties at room temperature. Thus, we developed the IRIS alloy (Ti-48Al-2W-0.08B). Its microstructure and mechanical properties are described here.

\section{INTRODUCTION}

After a first very successful implementation of TiAl alloys in blades of low pressure stages of aircraft engines [1], a real breakthrough in term of manufacturing process and chemical composition is required to push forward this industrialization in more constrained stages (closer to the combustion chamber) or into new generation engines, in order to increase the service temperature in the range of $800^{\circ} \mathrm{C}-900^{\circ} \mathrm{C}$. Interestingly enough, such an objective is in line with turbocharger applications in the automotive industry, especially for gasoline engines. Centrifugal casting [2], forging [3] and extrusion [4] are known as conventional processes which are able to generate alloys with interesting properties and which have been subjected to extensive technical developments from the TiAl community over the last two decades. In a general manner, alloys with high mechanical strength can be achieved through the application of post-thermal treatments. Furthermore, the powder metallurgy (PM) route is also worth to be investigated since homogeneous, texture-free microstructures with very reproducible mechanical properties can be generated. More recently, the PM route paves the way to additive manufacturing (AM). Several processes, such as Electron Beam Melting (EBM) [5,6], Laser Metal Deposition (LMD) [7,8] and 
Selective Laser Melting (SLM) [9,10], are thus currently investigated. However, even though these techniques show promising capabilities in net-shaping, the as-printed material performance is still to be improved, notably due to residual stresses and porosity. In this respect, the control of the aluminum content and the obtention of homogeneous microstructures are key issues. It is therefore important to carefully adjust the thermal treatments in order to obtain satisfactorily mechanical properties. In the authors' opinion, specific chemical compositions should be developed toward the process used as the thermal history will vary a lot, notably between processes that involve repeated melting and fast cooling and those that just require solution treatments. Of course, economic and technologic considerations are of primary importance on the determination of the future production processes of $\mathrm{TiAl}$ parts.

In this context, during the last decade, CEMES and ONERA have extensively investigated Spark Plasma Sintering (SPS) for TiAl-based alloys [11]. SPS is a consolidated powder metallurgy process using a direct pulsed current for rapid consolidation. This fast heating by Joule's effect enables one to obtain original microstructures with a high control of the temperature, leading to enhanced properties. The aim of the present paper is to first, explain the path followed to develop an alloy specifically designed for the SPS process and second, describe the microstructure and mechanical properties of the resulting as-SPSed IRIS alloy. All this work was performed under the aeronautic engine application framework, with the objective of obtaining a TiAl-based alloy offering high creep resistance at high temperatures together with a room temperature elongationto-failure greater than $1 \%$, eventually $1.5 \%$.

\section{EXPERIMENTAL DETAILS}

Fig. 1a presents a schematic representation of the SPS process [12]. A full densification is reached thanks to the simultaneous application of a high intensity direct pulsed current and a mechanical load on the powder encapsulated in a graphite set-up. The temperature rise is typically conducted at a hundred degrees per minute followed by a plateau of a few minutes after reaching the dwell temperature. Loading is generally applied at the onset of the cycle and removed at the end of the temperature plateau. This thermomechanical cycle determines the microstructure and so the mechanical properties of the resulting material. For a more comprehensive description of the process and its capabilities, the reader is invited to refer to our previous work in Ref [13]. Another important advantage of the SPS is the possibility to directly sinter complex-shape components [14, 15]. Fig. 1b shows a near-net shape high pressure blade obtained in one single SPS run. The shape of the blade was given by the graphite set-up, initially designed to form the counter-part.

Over this research program, properties of the alloys have been measured by performing roomtemperature tensile tests at a strain rate of $10^{-4} / \mathrm{s}$ to determine the alloy ductility and by tensile creep experiments performed at $700^{\circ} \mathrm{C}$ under $300 \mathrm{MPa}$ to evaluate the alloy strength at high temperature. The microstructures have been characterized by Scanning Electron Microscopy (SEM) using BackScattered Electrons (BSE) imaging. Table 1 summarizes the chemical compositions of the initial powders, the alloys microstructures and a summary of the corresponding mechanical properties.

\section{FIRST RESULTS WITH A GE POWDER}

Fig. 2 presents various microstructures obtained with a GE48 powder (Ti-48Al-2Cr-2Nb) at different dwell temperatures, which are marked on the phase diagram of the binary alloy (Fig. 2e) 
[16]. Since $\mathrm{Cr}$ and $\mathrm{Nb}$ additions exhibit opposite stabilizing effects of the $\gamma$ and $\alpha$ phases, respectively, the phase transformation temperatures are not significantly affected, and therefore the binary alloy phase diagram describes satisfactorily the GE alloy. A dwell temperature located in the lower part of the $\alpha+\gamma$ phase field has led to the formation of a near $\gamma$ equiaxed microstructure made of $\gamma$ grains and $\alpha_{2}$ zones located at grain boundaries or at triple junctions (Fig. 2a). For a dwell temperature in the $\alpha$ phase field, a lamellar microstructure was obtained with grains reaching a few hundreds of micrometers, as a result of a rapid grain coarsening subsequent to a significant holding time within the single $\alpha$ phase field. For an intermediate temperature in the upper part of the $\alpha+\gamma$ phase field, a duplex microstructure made of $\gamma$ grains and of lamellar colonies was observed. The lamellar colonies which result from the lamellar precipitation in $\alpha$ grains during cooling, exhibit a reduced size $(20 \mu \mathrm{m})$ from the pinning by $\gamma$ grains. All these observations are consistent with the results obtained in the pioneer work of Kim et al. [17], who brought about a clear classification of the various TiAl microstructures as a function of their treatment temperatures. The present results demonstrate that the SPS process allows to reach conventional TiAl microstructures which are simply determined from where the dwell temperature is in the phase diagram, despite the fact that SPS is a very rapid process. Fig. 2 also displays the mechanical properties of these three generic microstructures. At room temperature, the duplex microstructure exhibits a quite interesting ductility, with a plastic elongation of $2 \%$. Consistently with an extended pile-up of dislocations at grain boundaries, a large size of lamellar colonies results in a limited plastic elongation of $0.6 \%$. The yield stress of the equiaxed near- $\gamma$ microstructure is much higher in comparison. In a previous study, we found it to be controlled by the size of the $\gamma$ grains [18]. The creep curves (Fig. 2f) confirm the strong resistance at high temperature of the lamellar microstructure with a minimum creep rate of $10^{-8} \mathrm{~s}^{-1}$ and a creep life of 1800 hours, which is attributed to the strengthening effect of the lamellar interfaces. On the other hand, the lower creep properties of near $\gamma$ equiaxed and duplex microstructures are controlled by the propagation of the deformation in single phased $\gamma$ grains. This first study greatly emphases the main challenge we set ourselves when working with TiAl alloys: improving the strength at high temperature without reducing too much the room temperature ductility. For this purpose, preliminary studies have been conducted and will be summarized in the following section.

\section{PRELIMINARY STUDIES}

To increase the strength of the SPS-TiAl alloys, attempts were made to strengthen alloys with duplex microstructures by using the addition of elements such as $\mathrm{Nb}, \mathrm{Re}, \mathrm{W}, \mathrm{Mo}, \ldots$ Fig. 3 shows two typical microstructures obtained with the G4 $[19,20]$ and TNB $[21,22]$ powders (Table 1). Such a duplex microstructure consists of small lamellar and single phased $\gamma$ grains, with a grain size of 10-20 $\mu \mathrm{m}$. A few tiny B2 precipitates can be observed in the enlargement of Fig. 3a, in the case of the G4 alloy. In the case of the G4 alloy, the duplex microstructure was obtained through a treatment of 4 hours at $1320^{\circ} \mathrm{C}$ applied to a near $\gamma$ equiaxed SPS microstructure [20]. On the other hand, in the case of the TNB alloy, the billet was directly maintained during 30 minutes at the dwell temperature of $1330^{\circ} \mathrm{C}$ [21]. Fig. 3, c \& d show that both duplex alloys offer similar mechanical properties. In both cases, the plastic elongation is of $1.5 \%$ which is lower than that of the duplex

GE alloy but still higher than the industrial requirements. The creep curves are also very close with 
minimum creep rates of $3.10^{-8} \mathrm{~s}^{-1}$ and a creep life of about 1000 hours. These properties at high temperature are actually in the range of the ones obtained with the lamellar GE48 alloy and largely better that those of the GE48-duplex (Fig. 2f), demonstrating the positive effect of the addition of $\mathrm{Nb}$, Re and W. It's worth noting that such improvement is possible only if these heavy elements are uniformly distributed in the $\gamma$ and $\alpha_{2}$ matrix, as highlighted in our case by the very low fraction of B2 precipitates. However, the formation of duplex microstructures by the SPS process appears to be difficult because of a reduced temperature window and finally often requires the application of post-thermal treatments or a prolongated holding time at the dwell temperature. Thus, despite these promising properties, it appeared to us that a more interesting solution was to develop a lamellar microstructure with a reduced grain size in order to preserve the room-temperature ductility.

It is well known that the incorporation of boron is an efficient solution to limit the grain growth of TiAl alloys through the precipitation of borides which anchor grain boundaries [23-25]. Fig. 4 illustrates the effect of boron incorporation in GE based alloys processed by SPS [26]. For this purpose, a boron containing GE powder (called GE47B; Ti-47Al-2Cr-2Nb-0.6B) was used in comparison to a boron free one (called GE47; Ti-47Al-2Cr-2Nb). The microstructures which were obtained at the same dwell temperature $\left(1360^{\circ} \mathrm{C}\right)$ within the $\alpha$ phase field for both lamellar alloys, are compared in Figs. 4 a \& b. The GE47B grain size alloy is clearly lower than the GE47 one. For the GE47B powder, Fig. 4c reveals that the microstructure obtained at a higher dwell temperature $\left(1415^{\circ} \mathrm{C}\right)$, i.e. in the upper part of the $\alpha$ phase field, does exhibit similar grains size than at $1360^{\circ} \mathrm{C}$. The room-temperature stress-strain curves for four lamellar GE47B microstructures processed at four different temperatures within the $\alpha$ phase field are displayed in Fig. 4d. One can see that the incorporation of boron in SPS alloys allows a very limited grain coarsening at temperatures higher than the $\alpha$ transus, thereby stabilizing the microstructures and the mechanical properties of such lamellar alloys. In addition, the nucleation temperature for the $\gamma$ lamellar formation and consequently the lamellar width have been found to be increased by incorporating boron through the activation of a heterogeneous nucleation from the borides within the $\alpha$ grains [26].

\section{THE IRIS ALLOY}

Based on the results presented in sections 3 and 4, a chemical composition adapted to the SPS process was chosen. It includes a small amount of boron to control the grains size without forming extended borides that could be detrimental to the ductility [27]. To strengthen the alloy, 2 at\% of tungsten were also incorporated. Our approach was to use a strong strengthener element which was counter-balanced by a high aluminum content in order to maintain an adequate microstructure in particular for tensile ductility. For instance, Thomas et al. [28] has found that in as-Hipped condition, GE-48 exhibits a higher ductility than GE-47. Moreover, a TNM alloy processed by SPS [29] exhibits a very high strength at room and high temperatures but a limited ductility (0.9\% of plastic elongation). This behavior was attributed to the non-deformation of the lamellar colonies ascribed to a high proportion of $\alpha_{2}$ phase in such a low-aluminum content alloy. Thus, the IRIS alloy, Ti-48Al-2W-0.08B (at.\%), has been processed with different SPS conditions to optimize the microstructure [30-32]. Fig. 5 shows the microstructure obtained at a dwell temperature of $1350^{\circ} \mathrm{C}$ [31] made of lamellar grains with a size about 35-45 $\mu \mathrm{m}$. Interestingly, these lamellar colonies are 
surrounded by borders which are made of $\gamma$ grains. The width of the borders is about 5-10 $\mu \mathrm{m}$. Through a TEM study and ThermoCalc calculations, it has been emphasized that these borders result from the presence of remnant $\beta$ phase at the dwell temperature within the $\alpha+\beta$ phase field [31]. This $\beta$ phase surrounding $\alpha$ grains at high temperature in fact limits the $\alpha$ grain growth, in addition to the borides. An analysis by Transmission Electron Microscopy (TEM) of the orientation of B2 precipitates with respect to those of the $\gamma$ grains in which they are located, is indicative of the fact that these precipitates result from a secondary precipitation during cooling due to a supersaturation of tungsten in the $\gamma$ phase. EDS-SEM measurements have demonstrated that these $\gamma$ grain borders contain a significant amount of homogeneously distributed tungsten [32] which should correspond to the limit solubility of tungsten in the $\gamma$ phase. This is consistent with the measurement by atom probe analysis of niobium and molybdenum in the $\gamma$ phase of a TNM alloy despite the presence of a substantial amount of $\beta$ phase [33].

The stress-strain curve at room temperature and the tensile creep curve at $700^{\circ} \mathrm{C}-300 \mathrm{MPa}$ of the as-SPSed IRIS alloy are emphasized in Fig. 6 [32]. This alloy exhibits a plastic elongation at rupture of $1.6 \%$ and remarkable creep properties, with a minimum creep rate of $3.10^{-9} \mathrm{~s}^{-1}$ and a creep life of 4000 hours. The reasonably good ductility has been attributed to the high deformation of the $\gamma$ borders and also to the deformation capability of the lamellar zones owing to a low volume fraction of $\alpha_{2}$ phase (15\%) and to the significant width of the $\gamma$ lamellae $(200 \mathrm{~nm})[31,32]$. On the other hand, the creep strength is enhanced by the tungsten atoms located in these borders, which reduce the mobility of the climbing dislocations.

\section{CONCLUDING REMARKS}

In the present work, attempts have been made to use tungsten containing TiAl alloys for SPS processing in order to increase the service temperature of such intermetallic alloys for aeroengine and automotive applications. Similar compositions, namely ABB alloys, have already been investigated in the past by using the casting route [34,35], thus resulting in promising creep and fatigue properties. Compared to the casting route, the SPS route provides more homogenous microstructures, which lead to very reproducible properties. By finely mastering the thermomechanical SPS cycle, a very precise control of the microstructure is achieved, which is determinant for ductility. One point which is presently under investigation is the long-term ageing of the IRIS-SPS alloy at high temperature since microstructural instabilities have been detected in the ABB alloy [36].

Among the chemical compositions which have been investigated by SPS, the TNM alloy also provided high standard mechanical properties following the requirements used in the present work [29]. The creep strength of TNM-SPS is very similar to that of IRIS-SPS. At room temperature, a higher yield stress but a lower plastic strain have been measured for TNM-SPS (Table 1). This reduced ductility has been attributed to the non-deformation of the lamellar colonies, even though some evidence of the room-temperature deformation of B2 grains has been shown through a TEM analysis.

In a general point of view and regarding the question addressed in the present paper which is to attain a service temperature range of $800^{\circ} \mathrm{C}-900^{\circ} \mathrm{C}$, complementary investigations are still needed. 
However, this work satisfactorily shows the potential of the PM+SPS route. Clear evidence has also been brought about the necessity to develop a special chemical composition for a given process to optimize the properties.

\section{ACKNOWLEDGEMENTS}

This study has been conducted in the framework of the cooperative projects "IRIS-ANR-09MAPR-0018-06" supported by the French Agence Nationale de la Recherche (ANR) and "ALTIAERO" project of the "IDEX-ATS" program supported by the Université Fédérale Toulouse Midi-Pyrénées, which are acknowledged. The CEMES group thanks the PNF2 for providing SPS facilities (Plateforme Nationale de Frittage Flash/CNRS in Toulouse, France). 


\section{REFERENCES}

1. S.F. Clark, 787 Propulsion System. Aero Quarterly; Available from:http://www. boeing.com/commercial/aeromagazine/articles/2012_q3/2/ (2012).

2. A. Royer and S. Vasseur, Casting Metals Handbook, vol 15, 9th edn (ed. Chairman D.M. Stefanescu), ASM International, Metals park, OH, (1988).

3. H. Clemens, W. Wallgram, S. Kremmer, V. Gunther, A. Otto and A. Bartels, Adv. Eng. Mater. 10, 707 (2008).

4. F. Appel, H. Clemens and H. Kestler, Intermetallics compounds 3, Progress (eds J.H. Westbrook and L. Fleisher) Chapter 29, p. 617, (2002).

5. D. Cormier, O. Harryson, T. Mahale and H. West, Research Letters in Materials Science, 4 (2007).

6. S. Biamino, A. Penna, U. Ackelid, S. Sabbadini, O. Tassa, P. Fino, M. Pavese, P. Gennaro and C Badini Intermetallics 19, 776 (2011).

7. M. Griffith, C. Atwood, L. Harwell, E. Schlienger, M. Ensz, J.E. Smugereskeym, T. Romero, D. Green and D. Reckaway, Proceedings of the International Congress on Applications of Lasers and Electro-Optics (ICALEO’98), vol. 1, Laser Institute of America, p. 1 (1998).

8. J.H. Moll, E. Whitney, C.F. Yolton and U. Habel, Gamma Titanium Aluminides 1999, eds. Y-W. Kim, D.M. Dimiduk, M.H. Loretto, H. Clemens and H.H. Rosenberger, The Minerals, Metals \& Materials Society, p. 255 (1999).

9. L. Löber, R. Petters, U. Kühn and J. Eckert, 4th International Workshop on Titanium Aluminides, September 13th - 16th, Nuremberg, Germany (2011).

10. L. Löber, F. P. Schimansky, U. Kühn, F. Pyczak and J. Eckert, Journal of Materials Processing Technology, 214, 1852 (2014).

11. A. Couret, G. Molénat, J. Galy and M. Thomas, Intermetallics, 16, 1134 (2008).

12. R. Orru, R. Licheri, A. Mario Locci, A. Cincotti and G. Cao, Materials Science and Engineering R63, 127 (2009).

13. T. Voisin, L. Durand, N. Karnatak, S. Le Gallet, M. Thomas, Y. Le Berre, J.F. Castagne and A. Couret A, Journal of Materials Processing Technology, 213, 269 (2013).

14. A. Couret, J.P. Monchoux, L. Durand, H. Jabbar and T. Voisin, Patent n ${ }^{\circ}$ PCT/IB2012/051527, Déposé le 31 Mars, (2011).

15. T. Voisin, J. P. Monchoux, L. Durand, N. Karnatak, M. Thomas and A. Couret, Advanced Engineering Materials, 1, (2015).

16. C. McCullough, J.J. Valencia, C.G. Levi and R. Mehrabian, Acta Metall., 37, 1321 (1989).

17. Y.W. Kim, JOM, 41, 241989

18. Monchoux J.P., J.S. Luo, Voisin T. and A. Couret, Materials Science and Engineering, 679, 123-132, 2016

19. M. Grange, J. L. Raviart and M. Thomas, Met. and Mat. Trans. A, 35A, 2087 (2004).

20. H. Jabbar, J.P. Monchoux, M. Thomas and A. Couret. Acta Materialia, 59, 7574 (2011).

21. F. Appel and M. Oehring, Gamma-Titanium Aluminide Alloys: Alloy Design and Properties. In: Leyens, C.; Peters, M. (Eds.): Titanium and Titanium Alloys, Wiley-VCH 89 (2003).

22. H. Jabbar, J. P. Monchoux, F. Houdellier, M. Dolle, F. P. Schimansky, F. Pyczak, M. Thomas, and A. Couret, 18, 2312 (2008).

23. U. Hecht, V. Witusiewicz, A. Drevermann and J. Zollinger, Intermetallics, 16, 969, 2008

24. D. Hu, C. Yang, A. Huang, M. Dixon M and U. Hecht U. Intermetallics, 22:68 (2012).

25. M. Oehring, A. Stark, J. D. H. Paul, T. Lippmann and F. Pyczak, Intermetallics, 32, 12 (2013).

26. J.S. Luo, T. Voisin, J.P. Monchoux and A. Couret, Intermetallics, 36, 12 (2013).

27. D. Hu, Intermetallics, 10, 851 (2002).

28. M. Thomas, J. J. Raviart and F. Popoff, Intermetallics, 13, 944 (2005). 
29. T. Voisin, J. P. Monchoux, M. Hantcherli, S. Mayer, H. Clemens and A. Couret, Acta Mat, 73, 107 (2014).

30. A. Couret Alain, J.P. Monchoux, M. Thomas and T. Voisin, Procédé de fabrication d'une pièce en alliage TiAl, FR1355393, Patent 11 Juin (2013).

31. T. Voisin, J. P. Monchoux, M. Perrut and A. Couret A, Intermetallics, 71, 88, (2016).

32. T. Voisin, J. P. Monchoux, M. Thomas, C. Deshayes and A. Couret, Metallurgical and Materials Transaction, 47, 6097 (2016).

33. T. Klein, M. Schachermayer, F. Mendez-Martin, T. Schöberl, B. Rashkova, H. Clemens and S. Mayer, Acta Mat, 94, 205 (2015).

34. V. Recina and B. Karlsson, Materials Sciences and Engineering, A262, 70 (1999).

35. J. Lapin and M. Nazmy, Materials Science and Engineering A 380, 298 (2004).

36. J. Lapin, A. Klimova and T. Pelachova, Scripta Mat, 49, 681 (2003). 


\section{Table Captions}

Table 1. Summary of the chemical composition, microstructure, and mechanical property of TiAl alloys obtained by SPS. YS is the Yield Stress, TE the Total plastic Elongation, $\mathrm{CR}_{\min }$ the minimum Creep Rate, $\mathrm{t}_{1} \%$ and $\mathrm{t}_{\mathrm{F}}$ the time to reach $1 \%$ of elongation and the time to reach the fracture, respectively.

\section{Figure Captions}

Fig. 1. Schematic drawing of the SPS process (a) and near-net shape high pressure blade obtained by SPS (b).

Fig. 2. Microstructures (a-c) and mechanical properties (d,f) of various GE48-SPS samples obtained at different temperatures as marked on the binary phase diagram (e).

Fig. 3. Microstructures (a-b) and mechanical properties (c-d) of G4 and TNB alloys densified by SPS.

Fig. 4. Microstructures and tensile curves of boron free (GE47; Ti-47Al-2Cr-2Nb) and boron containing (GE47B; Ti-47Al-2Cr-2Nb-0.6B) lamellar alloys obtained at various dwell temperatures. (a) GE47-1360 ${ }^{\circ} \mathrm{C}$, (b) GE47B- $1362^{\circ} \mathrm{C}$, (c) $\mathrm{GE} 47 \mathrm{~B}-1414^{\circ} \mathrm{C}$ and (d) tensile curves at $1340^{\circ} \mathrm{C}, 1362^{\circ} \mathrm{C}, 1389^{\circ} \mathrm{C}$ and $1414^{\circ} \mathrm{C}$ of the GE47B.

Fig. 5. Microstructure of the IRIS alloy densified by Spark Plasma Sintering.

Fig. 6. Tensile and creep 
Table 1. Summary of the chemical composition, microstructure, and mechanical property of TiAl alloys obtained by SPS. YS is the Yield Stress, TE the Total plastic Elongation, $\mathbf{C R}_{\min }$ the minimum Creep Rate, $t_{1 \%}$ and $t_{F}$ the time to reach $1 \%$ of elongation and the time to reach the fracture, respectively.

\begin{tabular}{|l|l|l|l|l|l|l|l|}
\hline \multirow{2}{*}{ Alloy } & \multirow{2}{*}{ Chemical composition } & \multicolumn{4}{c|}{ Room Temperature } & \multicolumn{2}{c|}{ Creep $-700^{\circ} \mathrm{C}-300 \mathrm{MPa}$} \\
\cline { 3 - 8 } & & & YS(MPa $)$ & $\mathrm{TE}(\%)$ & $\mathrm{CR}_{\min }\left(\mathrm{s}^{-1}\right)$ & $\mathrm{t}_{1} \%(\mathrm{~h})$ & $\mathrm{t}_{\mathrm{F}}(\mathrm{h})$ \\
\hline GE48 & Ti-48Al-2Cr-2Nb & Near $\gamma$ & 756 & 0,56 & $2.10^{-7}$ & 0.2 & 163 \\
\hline GE48 & Ti-48Al-2Cr-2Nb & Duplex & 542 & 1.96 & $10^{-7}$ & 8.8 & 189 \\
\hline GE48 & Ti-48Al-2Cr-2Nb & Lamellar & 444 & 0.57 & $10^{-8}$ & 3.4 & 1767 \\
\hline G4 & Ti-47Al-1Re-1W-0.2Si & Duplex & 520 & 1,43 & $3.10^{-8}$ & 71 & 1012 \\
\hline TNB & Ti-46Al-9Nb & Duplex & 694 & 1.47 & $3.10^{-8}$ & 40 & 943 \\
\hline IRIS & Ti-48Al-2W-0.08B & Lamellar & 496 & 1.6 & $3.10^{-9}$ & 46.5 & 4076 \\
\hline TNM & Ti-43.9Al-4Nb-0.95Mo-0.1B & Lamellar & 806 & 0.9 & $3.10^{-9}$ & 202 & 3994 \\
\hline
\end{tabular}
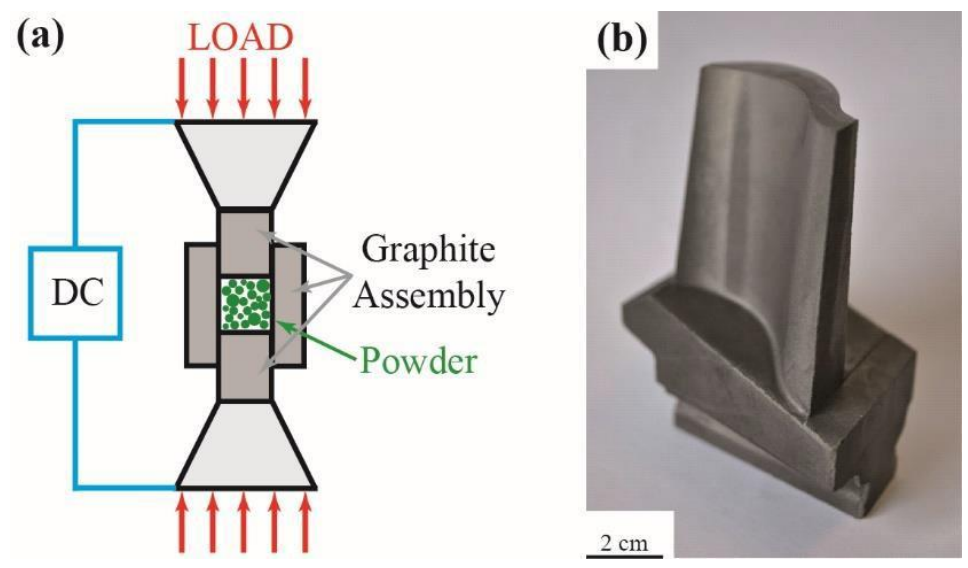

Fig. 1. Schematic drawing of the SPS process (a) and near-net shape high pressure blade obtained by SPS (b). 


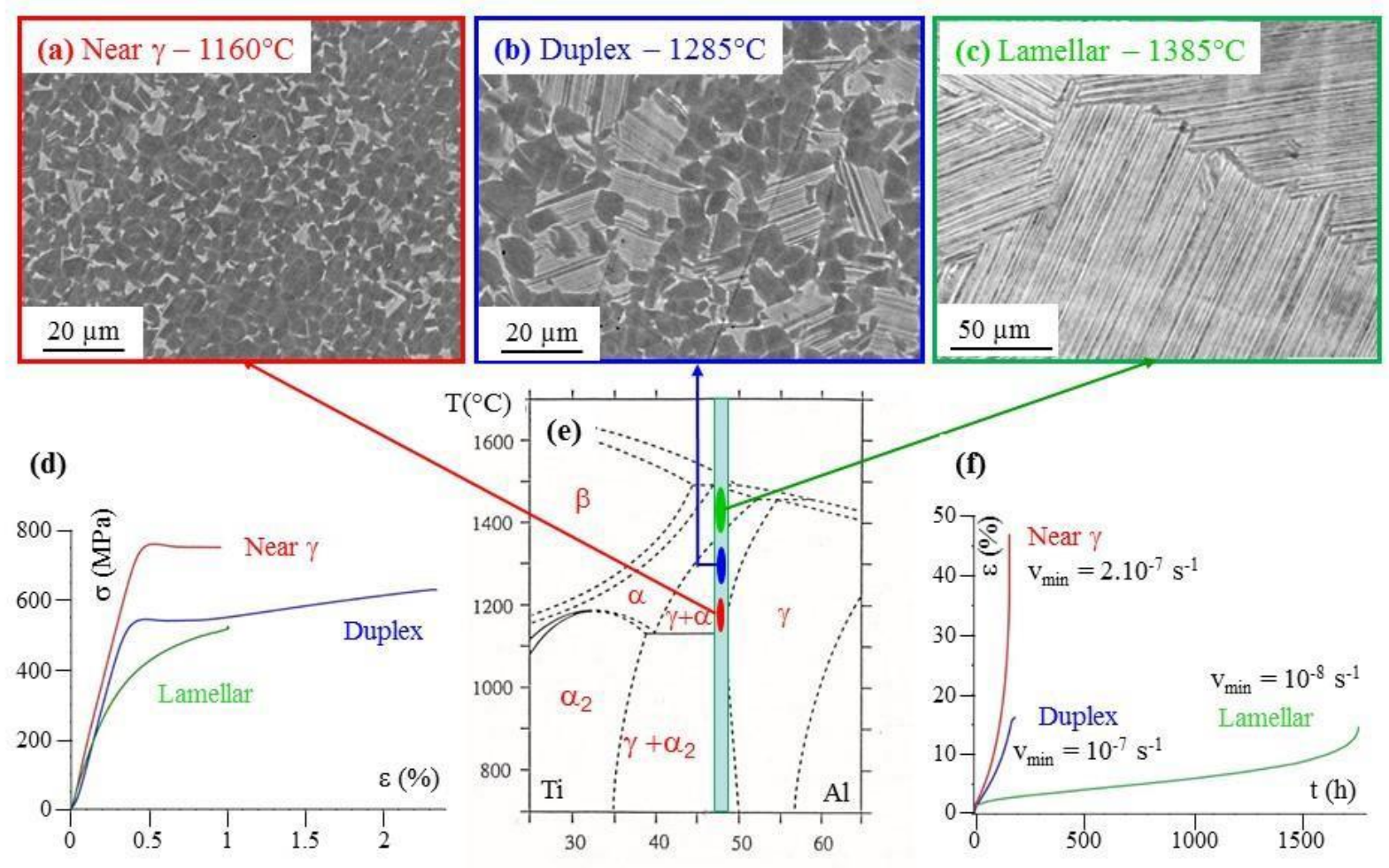

Fig. 2. Microstructures (a-c) and mechanical properties (d,f) of various GE48-SPS samples obtained at different temperatures as marked on the binary phase diagram (e). 

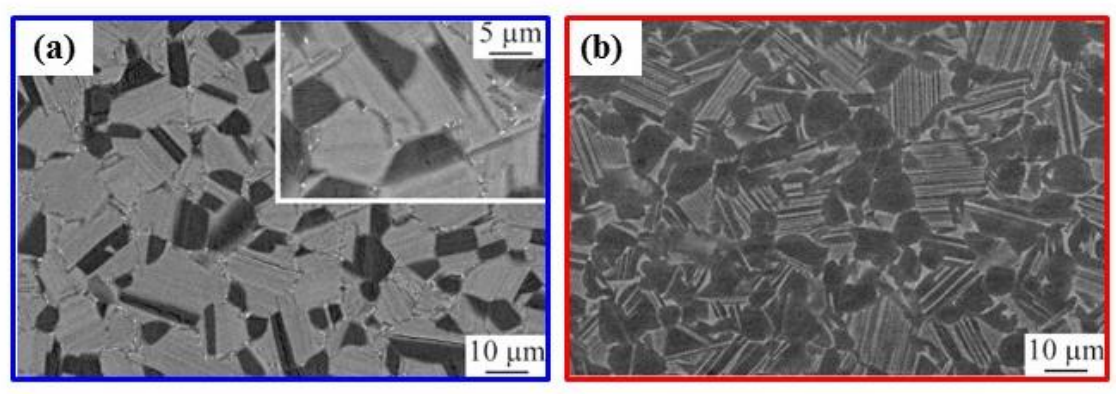

(c)

(d)
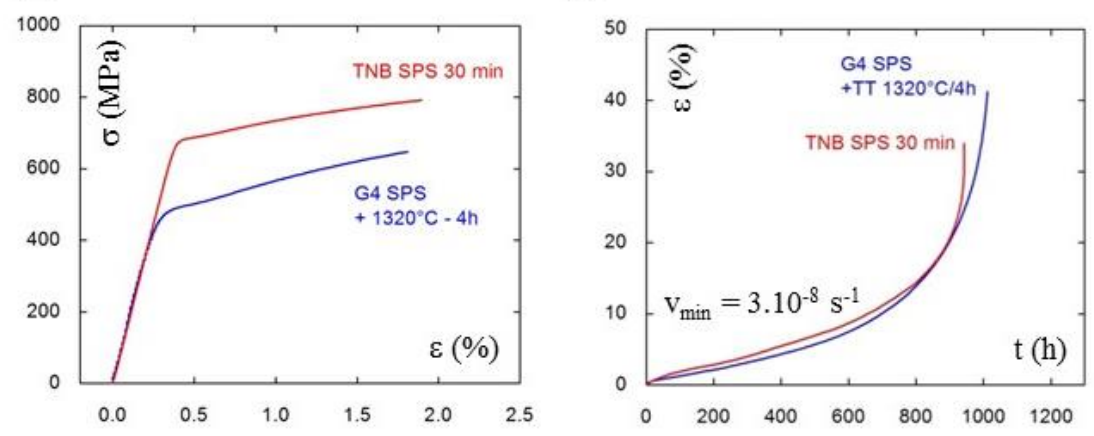

Fig. 3. Microstructures (a-b) and mechanical properties (c-d) of G4 and TNB alloys densified by SPS. 

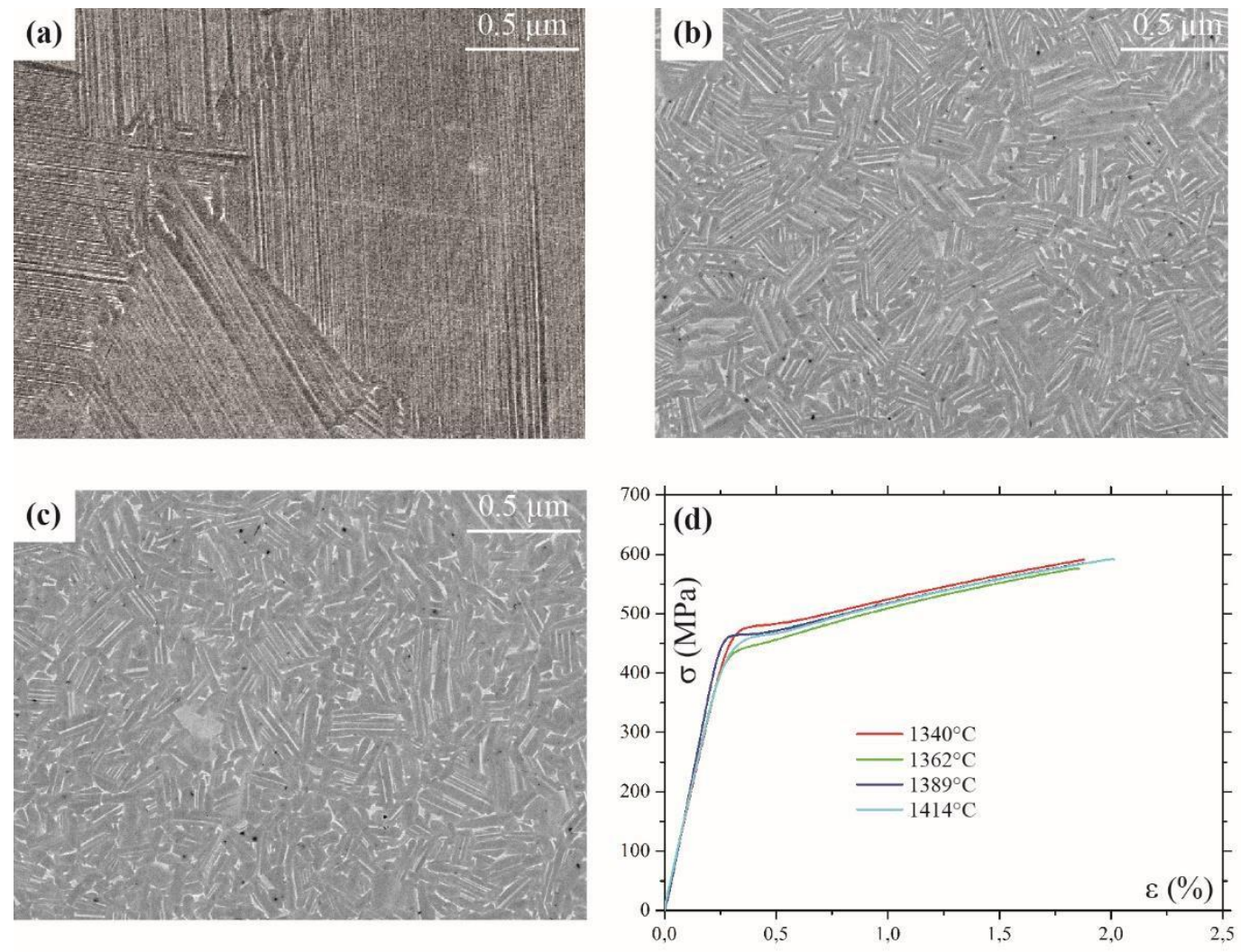

Fig. 4. Microstructures and tensile curves of boron free (GE47; Ti-47Al-2Cr-2Nb) and boron containing (GE47B; Ti-47Al-2Cr-2Nb-0.6B) lamellar alloys obtained at various dwell temperatures. (a) GE47-1360 ${ }^{\circ} \mathrm{C}$, (b) GE47B- $1362^{\circ} \mathrm{C}$, (c) GE47B $-1414^{\circ} \mathrm{C}$ and (d) tensile curves at $1340^{\circ} \mathrm{C}, 1362^{\circ} \mathrm{C}, 1389^{\circ} \mathrm{C}$ and $1414^{\circ} \mathrm{C}$ of the GE47B.

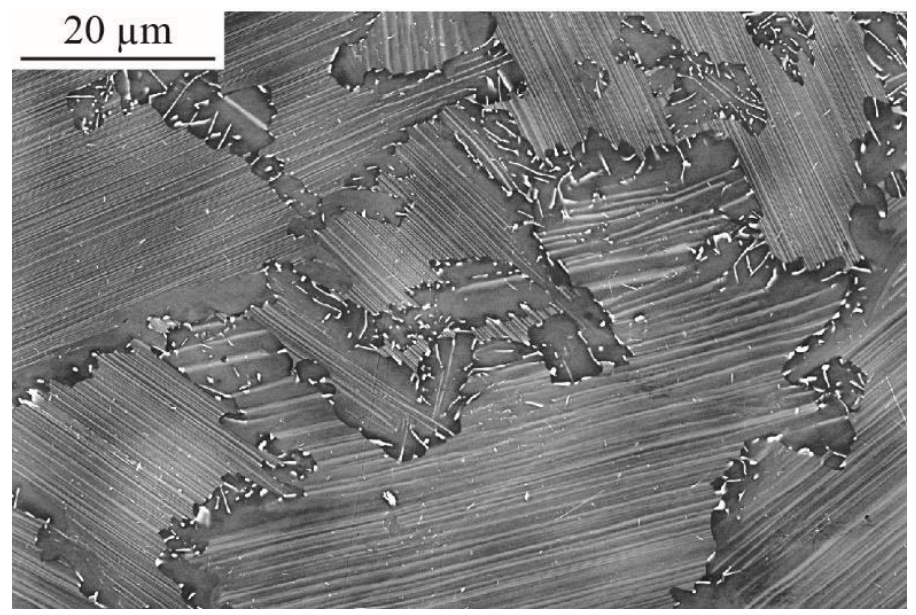

Fig. 5. Microstructure of the IRIS alloy densified by Spark Plasma Sintering. 
(a)

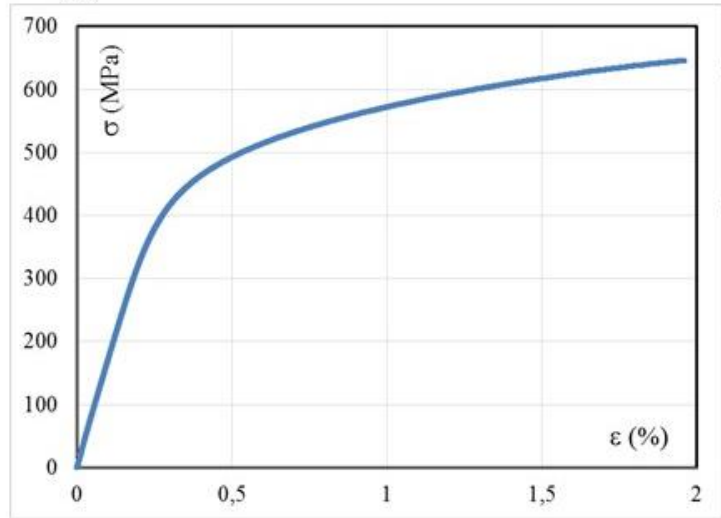

(b)

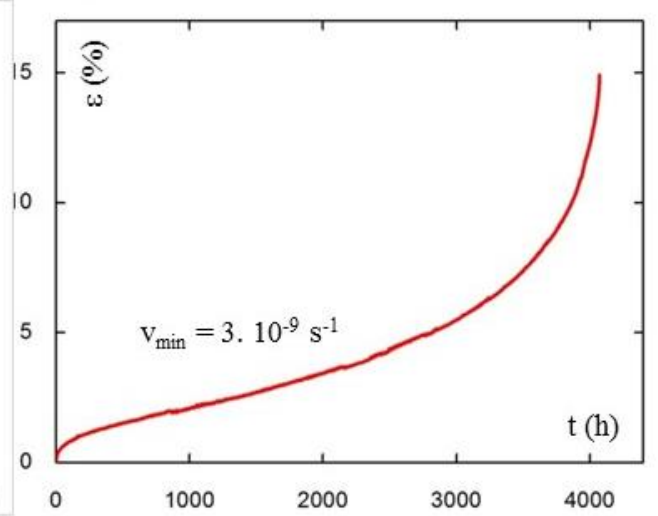

Fig. 6. Tensile and creep curve $\left(700^{\circ} \mathrm{C}-300 \mathrm{MPa}\right)$ of the IRIS alloy densified by SPS. 